\title{
The reintroduction of grid-connected alternatives into the planning of mass transportation systems in Colombia
}

\author{
A. E. Díez, P. Alzate, V. Restrepo \& A. Bohórquez \\ Universidad Pontificia Bolivariana, Colombia
}

\begin{abstract}
This work presents a synthesis of the technical, environmental and financial studies that contributed to the reintroduction of grid-connected alternatives into the planning of mass transportation systems in Colombia. With this effort, the Universidad Pontificia Bolivariana has played a decisive role in the reintroduction of trolleybus and tram systems in Colombia, which is fundamental to achieve the electrification of the transportation sector. The consequences of the electrification are a reduction in fossil fuel composition, air quality improvement, public health, and travel comfort upgrade.
\end{abstract}

Keywords: transport systems, alternative technology and urban planning, trolleybus, streetcars, electrification of public transportation.

\section{Introduction}

The transportation in Colombia is based on oil. Only one mass transportation system in Colombia is fed by electricity; that is the Medellin's Metro [1].

This paper is structured as follows; a first section will provide a historical background of the elimination of the former tram and trolleybus lines in Colombia, making a parallel with other regions of world. A second section analyses the recent planning practices in Colombia and their consequent BRT developments in the most important cities in the country that are exclusively based on internal combustion engines. The third section presents a technical assessment of gridconnected vehicles and others types of buses incorporating emerging technology developments, such as those with energy storage systems based on hydrogen, ultracapacitors and/or batteries now presented as alternatives to operate in BRT systems. Furthermore, the reluctance to use an overhead line, among other biased 
considerations, is playing an unfavourable role and delaying the electrification of public transportation systems. To solve the latter inconvenience, an approach based on the concept of Grid Connection Assistance (GCA) is proposed, to ease electrification plans. This concept and derivate arguments were useful in the task of demonstrating the overall convenience of using grid-connected vehicles. The parts involved in new transportation projects, from planning and gestor institutions, to operators, decision makers and politicians, are now more favourable to initiatives involving electric traction. Finally, a financial evaluation allows finding the conditions in which projects based on grid-connected vehicles to be more attractive, from the point of view of a profitable operation.

\section{Historical background of the elimination of the former tram and trolleybus lines in Colombia}

For half a century (1900s-1950s), mass transportation systems based on grid connected vehicles as tramways and trolleybuses were the core of urban transportation in America and Europe. By the decade of the 1950s, this kind of systems had disappeared from the urban landscape, under such suspicious circumstances that many academics believe in an orchestrated complot theory. In many countries the lobby of multinational oil and car companies against electrified systems was evident, aiming to increase sales of buses based on internal combustion engines, and consequently boost consumption of oil and tires.

About the last statement, a study included in the 1974 U.S. Government Report about the streetcar conspiracy, led by assistant attorney Bradford C. Snell [2, 3], claimed that "...three powerful automobile companies which eliminated competition among themselves, secured control over rival bus and rail industries, and then maximized profits by substituting cars and trucks for trains, streetcars, subways and buses. In short, it describes how General Motors, Ford and Chrysler reshaped American ground transportation to serve corporate wants instead of social needs."

However, other academics still dispute the conspiracy theory, arguing that the automotive industry boom was a natural consequence of the times of prosperity after World War II. Even today, many reject the advantages of systems based on trolleybus and streetcars over buses. For example, according O'Toole [4] "Streetcars cost roughly twice as much to operate, per vehicle mile, as buses. They also cost far more to build and maintain. Streetcars are no more energy efficient than buses and, at least in regions that get most electricity from burning fossil fuels, the electricity powering streetcars produces as much or more greenhouse gases and other air emissions as buses." It could be that in some cases, the statements related with build and maintain cost, correspond to facts, but comparison among capital cost of either streetcar or trolleybus system and buses, must be done taking into account the entire life cycles of the vehicles and infrastructure. However, the affirmation that there are not difference in terms of energy consumption among grid connected systems and buses is obviously biased, and the opposite is well established [5-8]; it could be assumed that an internal 
combustion engine vehicle consumes at least two times more energy that one equivalent electric vehicle.

Only a few cities in North America such as San Francisco, Seattle, Dayton, Philadelphia, Boston, Mexico City and Vancouver, have retained their tram and trolleybus lines. In South America, Sao Paulo and Santos, in Brazil; Cordoba, Mendoza and Rosario, in Argentina, still have trolleybus lines in operation. However, in the rest of cities, hundreds of kilometres of electrified lines of trolleybuses, trams and commuter trains, were eliminated. Some countries of central and west Europe, and mainly Asia, preserved and expanded the electrified lines, and these systems are recently facing a growing wave of appreciation from the users.

From the 1950 s to 2010 s, and coinciding with the boom of BRT developments, systems based on tramways and trolleybuses were practically ignored in urban planning around the globe, and some of the remaining systems in North and South America, were finally ended, like the trolleybuses lines in Edmonton [9] and Bogota [10]. Urban planners around the world have noticed the advantages of promoting public transportation, as priority to face mobility challenges in populated cities, and have found in the BRT an excellent alternative for this purpose. BRT are easy and quick to implement, compatible with private schemes of operation and relative cheap when compare with Metro solutions.

Colombia, in particular, reflected the best example of this trend, by 2015 BRT systems are operating in the most important cities such as Bogota, Medellin, Cali, Barranquilla, Bucaramanga and Pereira. There is some others systems under construction in Cartagena, Envigado and Ituagüi. However, grid-connected vehicle alternative was not considered or simply eliminated in early planning stages in all Colombian cases, as in the majority of the cases around the world.

Similar arguments to those used in the past to substitute tram lines, in favour to bus routes, quickly arise, when studding these planning decisions. Inflexibility, higher capital cost, visual pollution of overhead lines, among other factors are usually present, to reject electric systems. An attempt to an objective evaluation, of this consider decisive limitations, is present.

There is a renovated interest in tramway system in both Europe and America, and new systems have been built. However, this enthusiasm has not been translated to trolleybus systems, despite the obvious similitude. Today, there are tramway or light rail systems in at least 30 U.S. cities, still a pale number for a country with 51 states.

\section{Recent planning practices in Colombia}

Development of mass transportation systems is fundamental to increase the quality of life of societies and improve their sustainability. The positive impacts of introducing mass transportation system into cities of underdevelopment countries are even more notable, considering that many of those cities have grown fast and unorganized, without proper planning policies. In this kind of city, mass transportation systems are a key to directly improving quality of life of the citizens in aspects related to public health, by cleaning the air, reducing noise levels, and 
improving safety. In aspects related to economics, mass transportation systems have a positive influence by providing time travel and cost reductions. Even a worldwide benefit can be state, because important reduction of greenhouse gases emission and energy consumption is achieve through mass transportation initiatives.

The transport sector has been identified as one of the largest contributor to the emission of greenhouse gases. In 2011, the contribution of the transport sector to worldwide $\mathrm{CO}_{2}$ emissions was $22 \%$ [11] and it is estimated that by 2050 in Latin America the Transport Sector will contribute with $70 \%$ of overall emissions [12]. But this sector is also suitable for applying large scale technologies of low $\mathrm{CO}_{2}$ emissions, with important collateral benefits as air quality improvement, ride comfort increase and energy costs stabilization. The case of Colombia is especially important because of the low emission factor of the electric grid, (around $0.2 \mathrm{gCO}_{2} / \mathrm{kWh}$ ), thanks to an important hydropower contribution of $80 \%$ to electric energy generation.

It is in this context that the Colombian government has found the ground base to push initiatives in order to promote the implementation of mass transportation systems of medium capacity in cities with more than 300,000 inhabitants, and due the experience of Bogota, the BRT was the mode selected. BRT systems have been probe to be are very suitable solution for medium capacity transportation systems in underdevelopment countries. Only when a BRT has been pretended as a substitution of a high capacity Metro system, by overestimation of planers, saturation problems have produced a negative reaction of users. The best example of a saturated BRT is the Caracas line of Transmilenio, Bogota.

To push a BRT system into a city, the usual practice is to create state-owned company, responsible for promoting the project. This company is dedicated to the design of the system, build the infrastructure, develop the operational design under a legal, technical and financial structure, and finally, lead the bid process to concession the operation, usually to a private company, for a period that for Colombia has been between 10 and 15 years. The private company has to assume the capital cost of the buses and ensure operational directions, covering the associated cost. If incomes are lower than expected, because of a low demand, a minimum profit to the operator is defined, and has to be cover by the city budget. If a surplus is generated, this is divided between the company and the city, in proportions that vary depending on a previous negotiation. This excessive consideration in favor to private operators was very important to ease the process of implementation of Transmilenio system, because transporters have had great political influence in all Colombian capitals. Many believes that without private involvement, the process would have failed. Now this scheme is subject to severe criticism by public opinion [13].

For the construction, the practice is that the nation contributes with $70 \%$ of the funds, and the city $30 \%$. Despite infrastructure is assumed by the state and the system operated by a private, the external benefits of the projects are calculated and considered the economical profit to the state. 


\subsection{Externalities estimations}

In 2013, the Ministry of Transport of Colombia made a public offer to fund a mass transportation system that will demonstrate the greatest reductions of Greenhouse Gas Emissions according to an evaluation using the Transport Evaluation Models for Projects - TEEMP - developed by Clean Air Asia, together with ITDP, ADB, Cambridge Systematics and UNEP-GEF. The TEEMP is a tool that estimate emissions of a project under different scenarios, and evaluates short and long-term impacts of the mass transportation project. This methodology mainly weighs the impacts of $\mathrm{CO}_{2}, \mathrm{PM}$ and NOx from data collected during the feasibility stage of the project up to the actual operations. TEEMP estimated the direct emission savings according to mode shift, and indirect savings correspond to land use and dissemination impact. The dissemination impact foresees possible benefits of the replication of the solution, in similar cities.

Table 1 illustrates results obtained for a BRT project in Medellin, Colombia evaluated using the TEEMP model. The emissions related with mode shift are easy to assess and justify, because these are a local inventory of the vehicles to be substitute. The main component of the mode shift is to replace small buses that operate in low controlled schedule, with undefined stops and on-board payment, with less, but larger buses with defined stops, pre board payment, and strict operational schedules. According to the experience in other BRT implementations around the world, local information, and the longitude of the BRT project, the model estimated a reduction in emissions of 832995 tons of $\mathrm{CO}_{2}, 759$ tons of PM and 5254 tons of NOx. Less easy to justify is the estimation of the reductions associated with land use and dissemination impact (DI). The land use (LU) change depends a lot of the local construction dynamic. The dissemination factor cannot be used for overall emission impacts, because it would yield to an overestimation

Table 1: $\quad$ BRT project emissions in Medellin (20 years).

\begin{tabular}{|c|c|c|c|c|}
\hline \multirow{2}{*}{ Type } & \multirow{2}{*}{ Mode } & \multicolumn{3}{|c|}{ Emission (Ton) } \\
\hline & & $\mathrm{CO}_{2}$ & PM & NOx \\
\hline \multirow{3}{*}{ Savings } & Mode Shift & 832995 & 759 & 5254 \\
\hline & Land Use (LU) & 1369012 & 688 & 0 \\
\hline & Dissemination Impact (DI) & 1473700 & 9685 & 35160 \\
\hline \multirow{2}{*}{ Emission } & Construction & 64381 & 0 & 0 \\
\hline & Operation (CNG) & 334035 & 0.91 & 354 \\
\hline \multirow{3}{*}{ Net savings } & Total excluding DI & 1803591 & 1446.09 & 4900 \\
\hline & $\begin{array}{l}\text { Total excluding DI and LU } \\
\qquad(\mathrm{CNG})\end{array}$ & 434579 & 758.09 & 4900 \\
\hline & $\begin{array}{l}\text { Total excluding DI and LU } \\
\text { (electric) }\end{array}$ & 2134251 & 1447 & 5254 \\
\hline
\end{tabular}


of reductions, by overlapping them in several projects. It is not a conservative approach. Construction emission is calculate according to standard use of materials such as concrete and steel in similar projects. Finally, operational emission's estimation depends on the fuel selected (diesel or natural gas). Sadly, in this methodology, full electric operation is not consider in TEEMP, despite these results support the premise to invest in an electric transport, to reduce $90 \%$ the $\mathrm{CO}_{2}$ operation emission and to zero air quality pollutants.

\section{Technical assessment of grid-connected vehicles and other types}

\subsection{The BRT bus typology problem}

In the case of urban bus mode, either normal service or Bus Rapid Transit scheme, a discussion about the most suitable bus technology has emerged. Clean diesel, compressed natural gas, battery, fuel cell, hybrid diesel-electric and trolleybuses, are among a wide spectrum of alternatives that affect the decision making. As pointed above in Colombian case only diesel and gas natural have been considered.

Many cities have had experimented this debate recently, and some cases are deserve to be highlighted, such as Edmonton, were trolleybuses lines ceased in 2009 , and instead hybrid buses are used to operate the routes. In 2014 Wellington [13] transport authority announced that is considering doing the same, despite important reluctance of the public. In the other hand in 2012 Vancouver, Seattle, San Francisco and Dayton (USA), decided to renew their trolleybus fleet, and Leeds (UK) is considering a new trolleybus line, based on comparative studies among different bus technologies. Toronto transport authority also conducted a comparative study, resulting in favour to hybrid buses.

Locally, in Medellin, an intensive debate related to the choice of the typology of the Bus Rapid Transit of the city, Metroplus, took place in 2008. In that moment the three option considered were diesel, Compressed Natural Gas (CNG) and Electric Trolleybuses. Private operators tends to prefer the diesel alternative, while the public utility of the city along the transport and environmental authorities defended the CNG buses. Finally, a University -UPB - and Metro of Medellin, presented studies recommending the use of electric trolleybuses. Decision was favourable to CNG. However, the pressure of the public opinion, supporting the recommendations given by the UPB and Metro, led to understand the importance of the use of the electric energy in mass transportation systems. Typical reasons to avoid an electrified typology

By studying the reports released to the public in the cases mentioned above, and the experience of participating as part into the typology debate in Medellin and Bogota, the main arguments to avoid a technology with electric traction are: Greater initial cost of the electric vehicles, which in case on battery buses is related to the battery cost. 
Buses based on fuel cells are not a good option for Colombia. The initial cost and the need of a special infrastructure to supply the hydrogen is beyond discussion. In addition, the low efficiency of the complete process from the production of hydrogen to the wheels has demotivated the initiatives in that direction. In the future, if the cost of the technology allows, the use of Compressed Natural Gas Cells to produce electricity from this fossil resource could become interesting. In this case the use of grid connected vehicles will be still practical. Instead of equip each bus with a fuel cell; the conversion would take place in a specialized and substations, connected to the natural gas supply. This centralized scheme provides advantages like security because electricity is safer to transmit and distribute, and reliability because is easier to manage one fuel cell and the associated accessories like tanks, than one in each vehicle.

In the trolleybus case, the cost comes from market condition of restricted production, something that is not the case of Russian and Chinese markets. Investment in electric infrastructure, which in case of battery buses is related to charging stations, while trolleybuses needs overhead lines and its accessories; poles and traction substations.

Oddly, other factor against the use of grid-connected vehicles is the expectancy on a near-future availability of low cost battery electric buses, and even, there is confidence in other emerging technologies such as ultra-capacitor or fuel cells, which do not require overhead lines.

To refute these arguments, the explanation of the architecture of the power train of the electric bus is very useful. When is clear to the operator, that the battery, the grid connected, and the fuel cell powered buses, have very similar motors and power electronic-drivers, is easy to show them that the grid connected vehicle could be equipped with the energy storage system that, emerging in the future, will allow greater grid independence. By then, the feeding infrastructure will be still useful to recharge the buses. In the worst case, the overhead cooper line could be sale for use in other projects. Operators have to realize that the investment in a trolleybus is a robust one, easy to adapt and update through the years.

Finally, there is a great reluctance to overhead lines, from urbanist, architects and politicians. The visual pollution as a strong argument against trolleybuses and tram systems is always presented (oddly, this reluctance is less in tram case despite the obvious similarity between modern trolleybuses and streetcars). This argument among with the capital cost is one the greatest motivation to develop modes to avoid an overhead line. Against this argument, the use of imagery that shows examples (see fig. 1) of proper integration of the overhead line with light poles and trees, has proved to be effective in order to ease acceptance among the community. Overhead line accessories also would be simpler, so their visual impact reduced, if vehicles are conceived to operate using the energy storage system, in special cases like squares and round points.

Battery buses currently have an operative range limitation, and the subsequent weight-range dilemma, consisting in the directly dependence of range against batteries weight, and consequently, passenger capacity has to be sacrificed in order to meet BRT requirements. 


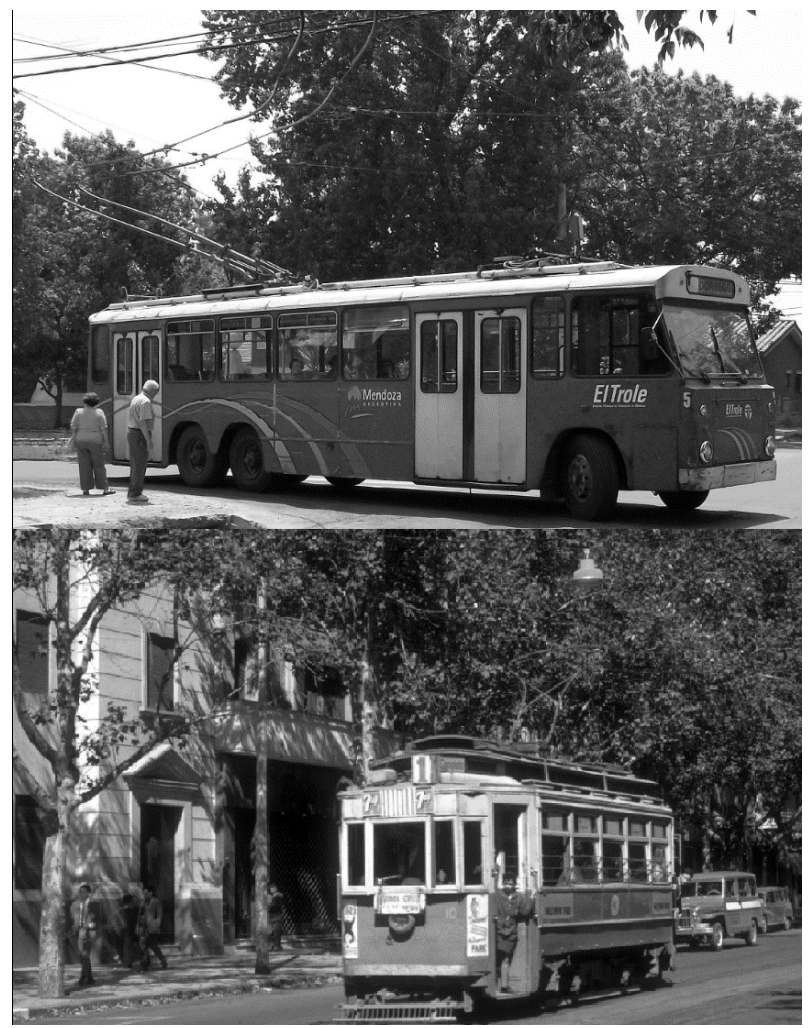

Figure 1: Examples of integration of overhead lines and trees (photography by Allen Morrison).

\subsection{BRT energy focus problem}

The problem statement, which subordinate the bus typology merely to the energy storage device used by the bus, is very simplified and could give wrong conclusions as a result. An approach in which the storage device becomes a complement (or combinations of several energy storage or supply systems) is more convenient. Following the usual problem statement, manufactures and supporters of each of the energy storage technologies, have claimed their own solution to the problem of operating a transport system based on buses, by solely using batteries, ultra-capacitors or fuel cells, among other alternatives. Only recently, some hybrid system combining two or more storage devices of different characteristics have been presented. The Trolleybus Optimized System Alimentation (TOSA) uses ultra-capacitors for fast charge in stations and high power demands, and batteries, for slow charge in the night, and low power supply. Unfortunately, the bus exclusivist approach, according to the type of energy storage device (battery bus, hydrogen bus, ultra-capacitor bus), has its origin in what may be considered the paradigm of the independence of the grid. In other words, the vehicle can operate 
indefinitely without connection to the source like overhead lines or rails. The origin of this paradigm can be traced to the animosity to use of overhead contact lines, commonly (and incorrectly) called catenary.

\subsection{Grid Connection Assistance}

The use of an infrastructure to power the vehicle from the Grid Connection Assistance (GCA). This assistance from the grid allows vehicles using this energy storage system; break the barriers that limit its widespread use, limited usually due the following restrictions:

Range: the use of grid assistance resolves range constrains, that are critical in battery and ultra-capacitor technology. This is critical in intensive operation systems as Transmilenio main routes.

Climbing capacity: with the assistance the operation in high gradients (beyond diesel buses capacity) is granted, feeding infrastructure would be installed only in sections where required. This is very important in Latin American cities, usually situated in hilly terrains.

Overweight: assistance with the system's network connection, allows reduce the weight of vehicles as required, increasing vehicle effective passenger capacity, critical in high intensive operational schemes.

The use of high consumption auxiliary services such as heating and air conditioning is restricted because this represents a critical reduction of the range. Grid connected vehicles have no range affectation. In tropical countries air conditioning could be required for many cities.

Flexibility: each operator could define vehicle specifications, depending on the circumstances of their system.

Range loss: With aging, batteries loss capacity. This is critical in intensive operation, like BRT systems.

The trolleybus BRT system of Quito is probably the best reference of GCA system operating in Latin America nowadays. This system has been in operation since 1995 with great success, and without fleet renovation. The rolling stock consist trolleybuses equipped with diesel engines for dual operation. The closeness to Colombia allows to extrapolate many of the operational data to perform financial assessments for future projects in Colombia. A trolleybus pilot project built into the campus of UPB in 2012 allowed to complete operative and infrastructure cost models [1].

\section{Financial results}

The financial assessment compares only three suitable types of buses operating under similar conditions on the Line One of the Metroplus System. The selected types of buses were Diesel, CNG and GCA, which in this case correspond to a modern trolleybus with a diesel engine for independent operation. Table 2 presents the operational data, very typical for an average BRT.

The Financial Simulation Model assumes a GCA bus with a cost US\$600,000. This cost for the GCA bus is $50 \%$ higher than diesel and CNG alternatives. The 
Table 2: Operational data.

\begin{tabular}{|c|c|}
\hline Parameter & Value \\
\hline Route length $(\mathrm{km})$ & 26.54 \\
\hline Buses & 100 \\
\hline Yearly bus usage (km/year) & 74,825 \\
\hline Yearly grow rate of passengers demand & $0.5 \%$ \\
\hline
\end{tabular}

relative cost is calculated using the more expensive technology in each concession period, either 15 years or 24 years, as reference. The simulation takes into account expenses and cost associated with operations, maintenances, salaries, energy, gas, diesel, insurances, taxes, mayor parts and vehicle replacements. The information used was provided for the referents Transmilenio for diesel, Metroplus for CNG, and Trolleybus BRT system in Quito, for GCA. The final cost (COP) is the present value of the total funds required in the year 2017 including a $100 \%$ financing costs for rolling stock, paid within a period of six years (the results are shown in Table 3).

Table 3: $\quad$ Project cost.

\begin{tabular}{|c|c|c|c|}
\hline $\begin{array}{c}\text { Concession period } \\
\text { (years) }\end{array}$ & Bus type & Cost (COP) & Relative cost \\
\hline \multirow{3}{*}{15} & Diesel & $\$ 2,966,607,067$ & $98 \%$ \\
\cline { 2 - 4 } & CNG & $\$ 2,458,566,865$ & $81 \%$ \\
\cline { 2 - 4 } & GCA & $\$ 2,342,834,293$ & $78 \%$ \\
\cline { 2 - 4 } & GCA + Infrastructure & $\$ 3,016,755,598$ & $100 \%$ \\
\hline \multirow{3}{*}{24} & Diesel & $\$ 4,096,467,801$ & $100 \%$ \\
\cline { 2 - 4 } & CNG & $\$ 3,462,013,870$ & $85 \%$ \\
\cline { 2 - 4 } & GCA & $\$ 2,766,770,520$ & $68 \%$ \\
\cline { 2 - 4 } & GCA + Infrastructure & $\$ 3,440,691,825$ & $84 \%$ \\
\hline
\end{tabular}

Infrastructure cost was added to the model as the cost of the overhead line and its associated materials and systems such as substations, poles, etc. Normally, this infrastructure must be provided by the regional government and does not represent any cost for the BTR system, but it was included to show the economic benefits of the CGA at the end.

\section{Conclusions}

Since 2008, the university has had an in important role in promoting electric public transportation systems of medium capacity, in the main cities of Colombia. These electrified systems are propose to be based on electric grid connected vehicles such 
as trolleybuses and streetcars, but incorporating energy backup systems that could be either diesel engines or batteries.

The introduction of the concept of Grid Connected Assistance has been very useful to remark the differences between new rolling stock compare and former trams and trolleybuses. New vehicles are able to operate rational distances without the connection to the overhead line, increasing the reliability and operational flexibility. The studies have demonstrated the technical, financial, and environmental superiority of grid connected systems over other possibilities based on fossil fuels such as diesel and CNG, in Colombian case, but similar results are supposed to be obtain in other Latin America countries. This model of analysis and case study can be developed in other types of transportations systems adapting the main variables and operating conditions. Results from this model were similar to others results from the studies held in previous years by recognized academic and government institutions around the country.

Following these results, a change on planning practices occurred in Colombia, and the reintroduction of medium capacity systems operating with grid connected vehicles is now underway. Currently in Medellin a tram system is under construction, which supposes the return of this mode to Colombia. The city of Medellin also paid studies for another tram line, through the 80 avenue, which is only pending for a financial mechanism to start construction. In Bogota three other tram projects are in basic design stages, and the electrification of Transmilenio, one of the largest BRT systems in the world has successfully passed a prefeasibility study.

\section{Acknowledgements}

A special thanks to Mr. Allen Morrison who has contributed in a fundamental way by collecting the history of Latin American trams, and making it available to the public. This work was supported by COLCIENCIAS under the project "Desarrollo de Nuevas Líneas de Servicios Tecnológicos Basadas en Celdas de Combustibles" with code 121056236765 .

\section{References}

[1] Díez, Andrés, et al. Reintroduction of Trolleybuses in Colombia: An opportunity for the Development of Sustainable Transport. Proceedings of PICMET'12: Technology Management for Emerging Technologies, 2012.

[2] Snell, Bradford C. American ground transport. Jerome Skolnick and Elliott Currie, Crisis in American Institutions, pp. 276-289, 1974.

[3] Snell, Bradford C. The streetcar conspiracy. Lovearth.net 2001.

[4] O'Toole, Randal. The Great Streetcar Conspiracy. Cato Institute Policy Analysis, no 699, 2012.

[5] Dhakal, Shobhakar. Implications of transportation policies on energy and environment in Kathmandu Valley, Nepal. Energy Policy, vol. 31, no 14, pp. 1493-1507, 2003. 
[6] Kühne, Reinhart. Electric buses-An energy efficient urban transportation means. Energy, vol. 35, no 12, pp. 4510-4513, 2010.

[7] Farsi, Mehdi, Fetz, Aurelio, Filippini, Massimo. Economies of scale and scope in local public transportation. Journal of Transport Economics and Policy, pp. 345-361, 2007.

[8] Levinson, H. S., Strate, H. E., Edwards, S. R., \& Dickson, W. Indirect transportation energy. Journal of transportation engineering, 110(2), pp. 159-174, 1984.

[9] ETS Trolley Buses, The City of Edmonton, Online. http://www.gov. edmonton.ab.ca/transportation/ets/ets-trolley.aspx

[10] The Trolleybuses of Bogotá, Allen Morrison, Online. http://www.tramz.com/co/bg/b/be.html

[11] International Energy Agency. $\mathrm{CO}_{2}$ Emissions from Fuel Combustion, Highlights: France, 2013.

[12] Yan, F., et al. Global emission projections for the transportation sector using dynamic technology modeling. Atmospheric Chemistry and Physics, vol. 14, no 11, pp. 5709-5733, 2014.

[13] Moller, R. Una evaluación crítica de sistemas de buses de transporte masivo en Colombia. Revista Ingeniería y Competitividad, 12(2), 23-40, 2011.

[14] Wellington trolley buses' demise to cost more than expected, Stuff, Online. http://www.stuff.co.nz/dominion-post/news/67709963/Wellington-trolleybuses-demise-to-cost-more-than-expected

[15] Diez, A.E., Bohorquez, A., Velandia, E., Roa, L.F., Restrepo, M., "Modern trolleybuses on Bus Rapid Transit: Key for electrification of public transportation," ANDESCON, IEEE, pp. 1-7, 15-17 Sept. 2010. 